Energy and Thermofluids Engineering

Available at https://asps-journals.com

\title{
A Critical Review on Material Balance Equation
}

\author{
Mohammad Mamun Ur Rashid ${ }^{1 凶}$, M. Enamul Hossain ${ }^{2}$ \\ 1 Department of Petroleum and Mining Engineering Chittagong University of Engineering and Technology, Chattogram-4349, \\ BANGLADESH
}

2 Department of Petroleum and Energy Engineering, The American University in Cairo, EGYPT

\begin{tabular}{l} 
Received 2 September 2020 \\
Revised 24 November 2020 \\
Accepted 2 December 2020 \\
Published online: 27 December 2020 \\
\hline Keywords \\
Complex Reservoir \\
Fractured Reservoir \\
Dual Permeability \\
Dual Porosity \\
Reserve Estimation \\
Original Gas In Place
\end{tabular}

\section{Introduction}

MBE is recognized as one of the most efficient techniques to estimate the hydrocarbon reserve. In the case of a conventional hydrocarbon reservoir, a graphical representation of $P / Z$ versus $G P$ can be made. If there is no water influx, it gives a linear trend and this method is used to estimate the original-gas-in-place (OGIP) (Dake 1978). For using the conventional $\mathrm{MBE}$, fracture and other unconventional properties should be considered. To analyze reservoir performance, several endeavors have been accomplished by the material balance method.
Abstract: Engineers have been using the material balance equation (MBE) for almost the last five decades to estimate cumulative production. However, it still is an effective tool to estimate the original hydrocarbon (oil and gas) available in the reservoir. The conventional material balance method has been successfully applying for the regular structure of a typical reservoir. In this method, all formation properties are assumed constant. However, it is very important to take care of the alteration of rock and fluid properties concerning space and time during the production history of the reservoir. Therefore, there is an immense need to understand how rocks and fluid properties change with space and time. In this paper, a thorough review and critical analysis of MBE are presented so that researchers can find a solution to why and how the incorporation of continuous alteration phenomena is needed to be considered during the development of new and dynamic MBE. Besides, the need for incorporation of all unconventional properties is detailed in this review research This review will help the new researcher to get a guideline for starting further research on the material balance equation. This study makes a crucial scope for carrying research to make a way out for the nonlinear behavior of the reservoir. This article also shows how different unconventional properties of the reservoir have been overlooked in many researches works. Finally, a guideline is provided to overcome the previous challenges in estimating hydrocarbon reserve, and workflow is presented to develop a new dynamic MBE.

(C) 2020 The authors. Published by Alwaha Scientific Publishing Services, ASPS. This is an open access article under the CC BY license.

${ }^{\boxplus}$ Corresponding author. E-mail address: mamunpme@cuet.ac.bd

This work is licensed under a Creative Commons Attribution 4.0. License (CC BY 4.0) http://creativecommons.org/licenses/by/4.0/ 


\subsection{Complex Reservoir}

Structurally complex reservoirs are a specific class of reservoirs in which fault and fracture play an important role in petroleum trapping and production behavior. There is an increasing technical challenge to handle these behaviors accurately (Moller-Pedersen \& Koestler 1997; Coward et al. 1998; Knipe et al. 1998; McClay 2004; Swennen et al. 2004; Sorkhabi and Tsuji 2005; Lonergan et al. 2007). A significant number of hydrocarbons are trapped in these complex reservoirs. Production engineers face huge challenges to extract these remaining trapped hydrocarbons. The updated production tools are providing sufficient technology to produce hydrocarbon from these faulted and fractured reservoirs. However, improved analytical models are needed to optimize field development, rates of production, and ultimate recovery (Jolley 2007). This analytical model usually begins with imaging and mapping from the 3D seismic survey. A 3D structural framework model can be developed by using a newly developed modeling technique thatcan easily investigate the fault and fracture conditions of the reservoir (Badley et al. 1990; Needham et al., 1996; Rutten and Verschuren 2003). Figure 1 shows a geological formation of the structurally complex reservoir.

\subsubsection{Fractured Reservoir}

During the last few years, research on material balance has been conducted for the fractured reservoir to improve the reservoir analysis. However, all previous works apply to limited ranges of data. Porosity and permeability throughout the reservoir are assumed uniform in the case of conventional MBE. As a dual-porosity system is generated for the naturally fractured reservoirs (NFR), the assumption is not valid. The compressibility of fractures is much higher than the matrix. Besides, the porosity of

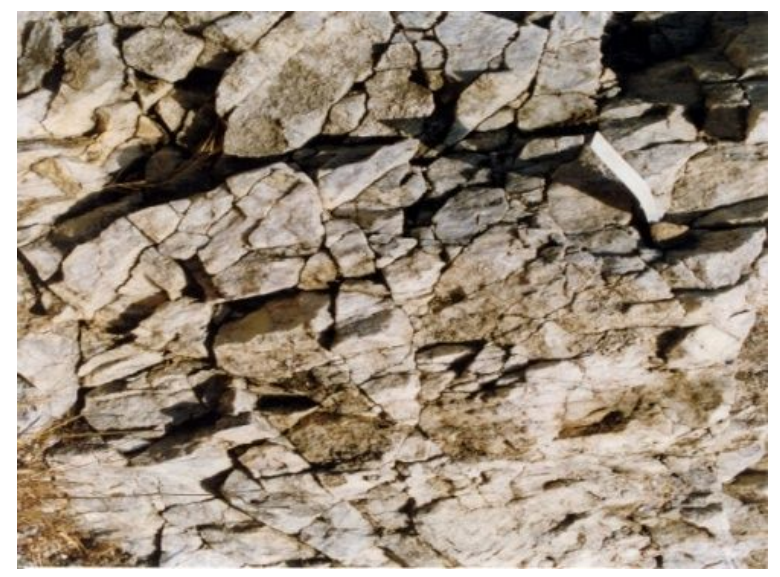

Fig. 1. A sample of structurally complex reservoirs. fracture and matrix changes when there is a change in pressure (Nelson 1985). Walsh (1994) developed a comprehensive straight-line method to estimate hydrocarbon reserve for the conventional reservoir and this method applies to a full range of reservoir fluids. This paper presents all previous works on the conventional reservoir in an organized way so that readers can capture the missing criteria for an unconventional reservoir without difficulty.

\subsubsection{Tight Gas Reservoir}

To produce natural gas at an economic rate from low permeability reservoir rock, massive hydraulic fracturing is required. This type of natural gas is known as tight gas. The matrix permeability of a tight gas reservoir is less than 0.1 $\mathrm{mD}$ and the porosity of the matrix is less than $10 \%$ (Ben et al., 1993, Sharif 2007). Some productive work was conducted on a tight gas reservoir by using MBE. Application of MBE to the tight gas reservoir is not straight forward; however, it can misinterpret the results (Hagoort et al. 2000). $P / Z$ vs $G_{p}$ graph exhibits the nonlinear behavior in the case of a tight gas reservoir whereas the conventional reservoir shows the linear trend (Engler 2000). The nonlinearity is related to the pressure measurement technique and reservoir characteristics. Nobakhtet al. (2010) introduced a simplified method to predict the production for the tight gas reservoir which exhibits extended linear flow periods. The advantages of this prediction method are: (i) only initial rate and original gas in place (OGIP) are the required parameters, and (ii) there is no need to forward the time step to calculate cumulative gas production (Morgan 2010).

\section{A Critical Literature Survey}

The material balance method is a great practice for reservoir engineers to find out the original-hydrocarbon-inplace (OHIP) (Moghadam et al. 2009). However, the same equation is not applicable for all reservoirs. Due to the diversity of the hydrocarbon reservoir, researchers developed numerous models based on the conditions of the reservoirs. For an unconventional reservoir, a simplified MBE was proposed by Jensen and Smith (1997).

\subsection{General Material Balance Equation (GMBE)}

Schilthuis (1936) primarily presented a general MBE for the homogeneous reservoir. In the hydrocarbon reservoir, to determine drive mechanism and estimate their performance Schilthuis' MBE was the only means 
until 1950. A very simple and spontaneous form of MBE by using figure 2 is:

$$
\begin{gathered}
{\left[\left(B_{t}-B_{o i}\right)+\frac{m B_{o i}}{B_{g i}}\left(B_{g}-B_{g i}\right)+(1+m) B_{o i} C_{T} \Delta P\right]+W_{e}} \\
=N_{p}\left[B_{t}+\left(R_{p}-R_{s i}\right) B_{g}\right]+B_{w} W_{p}-G_{i n j} B_{g i n j}-W_{i n j} B_{w} \\
B_{t}=\left[B_{o}+\left(R_{s i}-R_{s}\right) B_{g}\right] \\
C_{T}=\frac{C_{w} S_{w i}+C_{r o c k}}{1-S_{w i}}
\end{gathered}
$$

MBE is the simplest presentation of the mass conservation in a hydrocarbon reservoir. Mass conservation theory can be applied for the prediction of hydrocarbon in the reservoir which is known as the "material balance equation" (Havlena and Odeh 1963). The equation developed by Havlena and Odeh is the expression of the constant behavior of the reservoir. For developing this fundamental equation, they considered some assumptions. The straight-line method of $\mathrm{MBE}$ requires creating of the plot of a group of variables vs. other variable groups. With the increasing production from the different unconventional reservoirs, industries are inclined with modified MBEs. The model developed by Havlena and Odeh (1963) has many limitations. It is an established and proven fact that the reservoir shows linear behavior only for some instances.

In the majority of the cases, the reservoir shows nonlinear behavior. Walsh (1995) addressed that this non linearity appears when the properties of the reservoir alter during any change of the natural phenomena, and/or production. He presented a generalized MBE applicable to a reservoir where rock/fluid properties change. Buduka et al. (2015) showed the limitation of the straight-line method and provided a solution. Based on matching pressure and production data, they developed a mathematical model that is referred to the history matching. Therefore, there is an immense need for developing a comprehensive
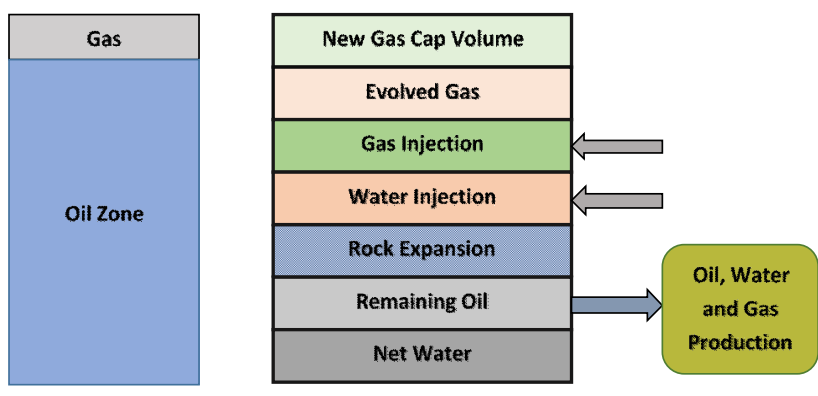

Fig. 2. Pore volume balance for material balance equation (redrawn from Ahmed et al., 2005). dynamic MBE where an option of considering the alteration of rock/fluid properties exists.

\subsubsection{MBE for Gas Reservoirs}

For the general material balance equation, some major assumptions were made (Ahmed et al. 2005): (i) the temperature, pressure, and porosity are constant within the reservoir, (ii) water is present in the water phase only, (iii) total thermodynamic balance i.e., uniformity of PVT data, (iv) production rate-independent fluid recovery, and (v) available production data which are reliable as well. The GMBE was formulated on a black oil reservoir and consequently, is not directly applicable for volatile oil or gas-condensate reservoirs. Besides, this model is not able to cover naturally fractured reservoirs as uniform porosity was considered (Bashiri et al. 2011).

\subsubsection{Shale Gas Reservoir}

The gas which is trapped in shale formation is known as shale gas. With the increasing interest in the USA and the rest of the petroleum world, shale gas has become an important resource (Stevens 2012). Some researchers are expecting that this type of gas will increase the energy supply throughout the world. Multiple porosities are the important characteristics of Shale gas reservoirs (Orozco and Aguilera 2017). These multiple porosities are: (i) adsorbed porosity, (ii) organic porosity, (iii) inorganic matrix porosity, (iv) natural fractures porosity, and (v) hydraulic fractures porosity (Aguilera and Lopez, 2013). Ignoring the gas dissolved in shale formation results in an uncertain estimate in the MBE method.

The conventional gas MBE was modeled for a volumetric reservoir. However, $\mathrm{p} / \mathrm{Z}$ vs. cumulative gas plot gives some unrealistic results in the case of some abnormal situations such as over-pressured condition (e.g., coal bed methane), and desorption condition (e.g., shale formation). Figure 3 shows $\mathrm{p} / \mathrm{Z}$ vs. cumulative production (Gp) plot for different reservoir conditions. From the figure, it is observed that all

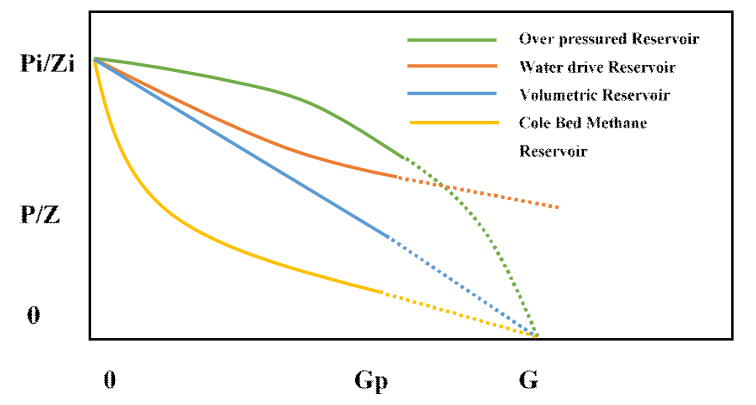

Fig. 3. Conventional $\mathrm{P} / \mathrm{Z}$ vs. cumulative production plot (Singh et al., 2013, redrawn) 
plots are nonlinear except for the volumetric one. This is because, in the straight-line method, only gas expansion was incorporated as a drive mechanism. There are different drive mechanisms involves based on different reservoir categories. In the water drive reservoir, water influx acts as a drive mechanism, formation, and residual fluid expansion acts as a driving force in an over-pressured reservoir. Singh et al. (2013) reported that gas desorption has a significant role in shale or CBM reservoir as a driving force.

\subsubsection{Abnormally Pressured Reservoir}

To calculate OGIP in the volumetric reservoir, the frequently recognized method is the MBE. Many production engineers follow this technique for abnormally pressured reservoirs and eventually ended up with a huge percentage of error in calculating the production estimation. The solution to lessen the error is to adjust rock and water compressibility between the conventional $\mathrm{p} / \mathrm{z}$ plot and the plot of the abnormally pressured reservoir (Ramagost and Farshad 1981). There are significant differences in reservoir properties between normally and abnormally pressured reservoirs. The changes in these properties have a significant impact on the accuracy of hydrocarbon reserve estimation. These variable pressure conditions are needed to consider the improvement of accuracy in reserve estimation.

The main statement of MBE for an abnormally pressured reservoir is the OGIP which is equal to the hydrocarbon withdrawals divided by the gas formation volume factor and water expansion. Mathematically, this can be written as:

$$
G=\frac{G_{p} B_{g}}{B_{g}-B_{g i}+\frac{B_{g i} \Delta p\left(C_{w} S_{w}+C_{f}\right)}{\left(1-S_{w}\right)}}
$$

On the other hand, Gonzalez and Blasingame (2008) developed a quadratic model of MBE for the abnormally pressured gas reservoir. In that model, they mainly focused on developing (i) a quadratic MBE model, (ii) plotting functions for the analysis of reservoir performance based on rigorous quadratic $\mathrm{MBE}$, and (iii) a dimensionless type curve solution. Mathematically, the model is written as:

$$
\frac{p}{z} \approx \frac{p_{i}}{z_{i}}\left[1-\left[\frac{1}{G}-\omega\right] G_{p}-\frac{\omega}{G} G_{p}^{2}\right]
$$

Where $\omega$ is defined as a function of cumulative gas production, $G_{p}$.

\subsubsection{MBE for Oil Reservoir}

Fattah et al. (2009) recommended a set of comprehensive relationships for material balance oil (MBO) model variables based on more than 2,000 PVT data points. He also incorporated the gas-oil ratio. England (2002) identified complexity for such approximation during the improvement of some correlations. Figure 4 shows the concept of the gas-oil ratio for MBE. The figure explained how the oil, gas, and condensate are separated from single-phase reservoir fluid. Based on reservoir conditions, different types of oil reservoirs are available in the world. The two most common oil reservoir types are (i) saturated reservoir and (ii) under-saturated reservoir. Approved and accepted material balance methods are available for these two types of reservoirs.

\subsubsection{Saturated Reservoir}

A reservoir is said to be saturated when its temperature goes equal or below bubble-point. This type of reservoir is also known as a multi-phase reservoir. Mosobalaje (2015) developed a method to estimate hydrocarbon for this type of the reservoir. This method has been applied to two reservoir models and found it very effective to predict hydrocarbon reserve through a numerical simulation study. Two profiles are correlated to get a production profile as a time function. Whenever well performance prediction is completed using the inflow performance relationship (IPR), cumulative oil production was attained from the applicable MBE. To verify this model, the author applied it to the solution gas drive reservoir model published by Camacho and Raghvan (1987) and Frederick and Kelkar (2005). Agbodike et al. (2019) provide an accurate pressure history prediction for oil reservoirs. This

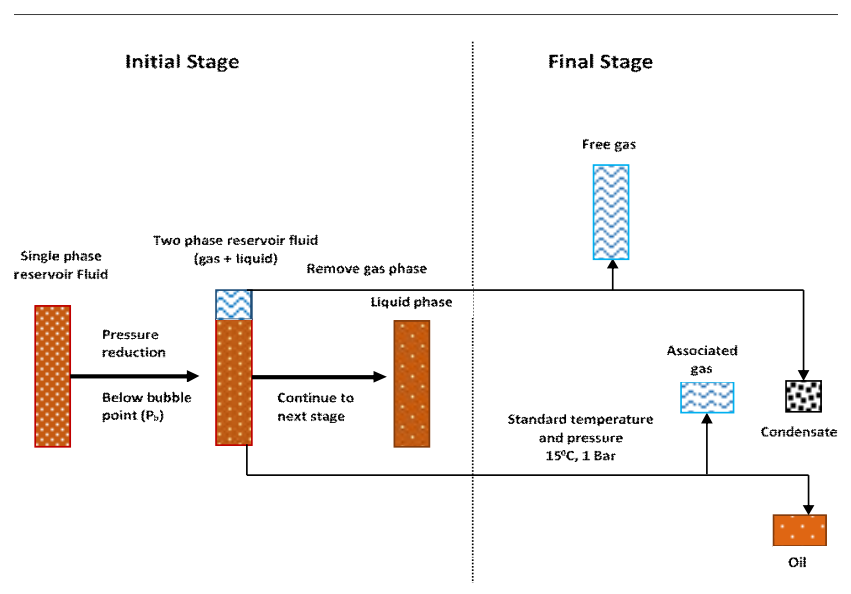

Fig. 4. Concept of Oil-gas ratio for generalized material balance equation (Graas et al., 2000) (redrawn). 
is a good method to estimate production in a field with limited bottom hole pressure (BHP) data.

\subsubsection{Under-saturated Reservoir}

When the reservoir temperature goes above the bubble point is known as an undersaturated reservoir. As the gas exists in a dissolved condition with oil, this type of reservoir is also called a single-phase reservoir. As there is a temperature difference between an under-saturated and saturated reservoir, a modified MBE should be used. Barry (1963) developed a model of MBE for a better estimation of an undersaturated reservoir. He incorporated the water drive condition during the development of his model. Walsh and Raghavan (1994) proposed a generalized material balance model thatapplies to the under-saturated volumetric reservoir. The author tried to eliminate assumptions that were considered by Havlena and Odeh (1963). Havlena and Odeh (1963) considered only gas expansion as a driving force. But in the majority of the cases, another mechanism also responsible for the driving force which has elaborately been explained in section 2.1.1.1.

\subsection{MBE for Fractured Formation}

In many reservoirs, the primary pathways for hydrocarbon migration and production are natural fractures and faults. Sixty percent of the world's remaining oil reserves exist in fractured formations (Harris and Weber 2006). Natural fracture is the macroscopic discontinuity of reservoir rock which affects the multiphase flow within the reservoir (Fig. 5).

Despite the presence of fractures in all reservoirs from geological and reservoir engineering points of view, a formation can be defined as a fracture only when it affects (i.e. either positive or negative) the flow of the fluid within the reservoir (Aguilera, 1995). Sometimes, a small

amount of hydrocarbon contained in the matrix can be easily produced where there is high permeability of the surrounding fractures which is frequently encountered in the Middle East. Aguilera used MBE for a saturated and

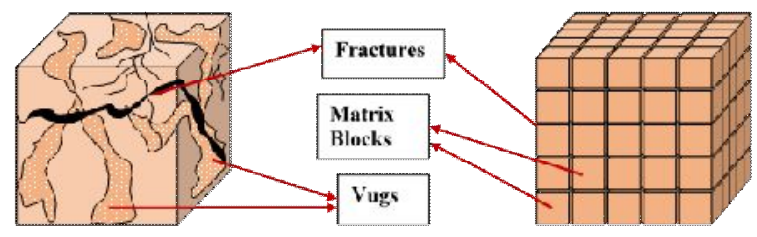

Fig. 5. The physical structure of the dual-porosity model (Redrawn from Warren and Root 1963; Kazemi 1969). undersaturated reservoir by considering the effective compressibility of matrix and fractures. A critical summary is given below about the research works conducted on the fractured reservoirs.

\subsubsection{Significance of Fractured Formation}

There is a huge impact of fractured formation on hydrocarbon production. By applying the role of the fracture condition of a reservoir, production rate and cumulative production can be increased. Huge research is going on to estimate the reserve by material balance technique considering the fractured condition. The importance of the fracture network is shown in Figure 6. A total of four cases of permeability $(k)$ and porosity $(\varphi)$ are shown in this figure. The figure shows that fault and fracture have a great effect on the porosity and permeability of a reservoir. From the figure, it is also clear that only the presence of fractures and faults is not enough to occur migration and storage of hydrocarbons.

There should have a good combination of porosity and permeability in the fracture to increase the storage capacity and to facilitate the flow of hydrocarbon. In the case of very poor porosity and permeability of the matrix, fractures provide both storage and flow pathways. The matrix of high porosity and low permeability contribute significantly to production and this type of combination is suitable for secondary and tertiary recovery.

There are three different types of fractures available in the reservoir. These are types I, II, and III, and all three fractures are created naturally. Table 1 and figure 7 shows the classification and role of the naturally fractured reservoir. Type I reservoir provides essential porosity and

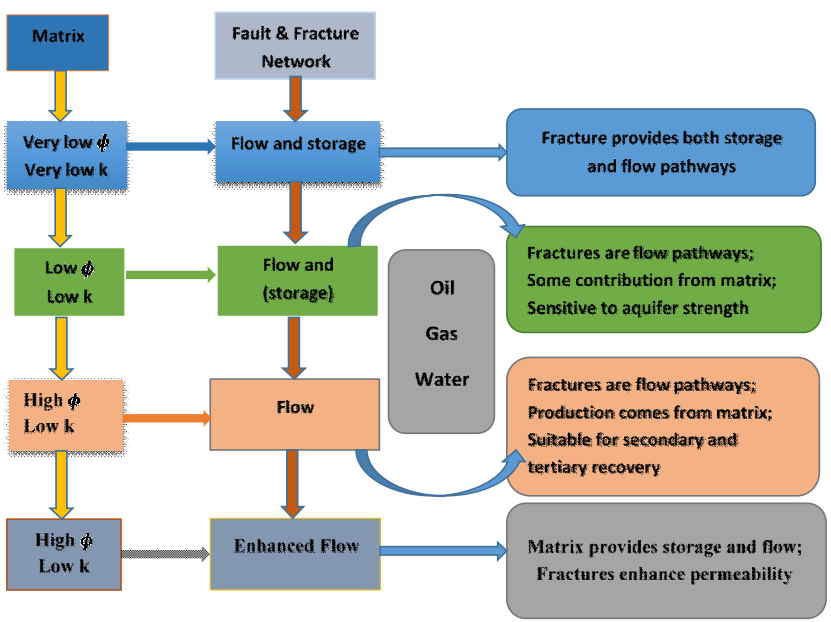

Fig. 6. A diagram showing the importance of fracture and matrix. 


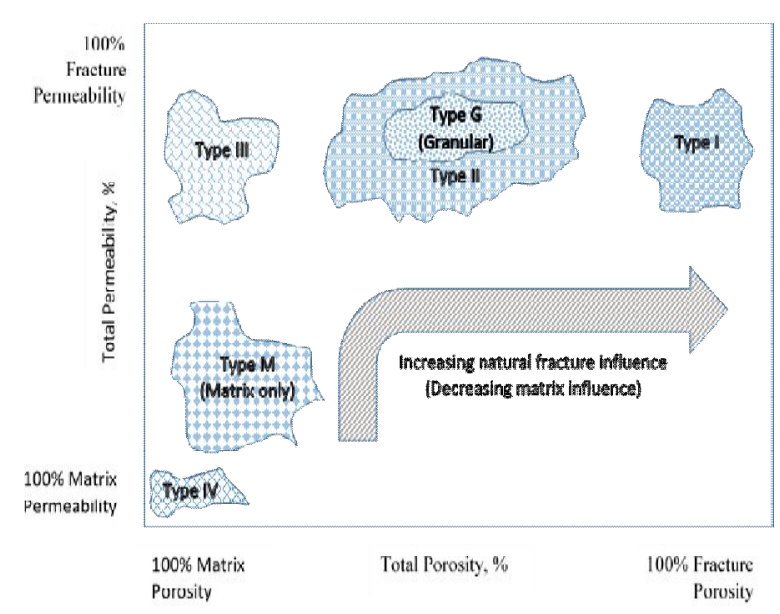

Fig.7. Influence of matrix and fracture on porosity and permeability in a reservoir (Nelson, 1982) (Redrawn).

Table 1 Classification of a naturally fractured reservoir.

\begin{tabular}{lll}
\hline $\begin{array}{l}\text { Type of } \\
\text { fracture }\end{array}$ & Characteristics & Contribution in production \\
\hline Type I & $\begin{array}{l}\text { Primary porosity }(\varphi) \\
\text { Primary Permeability (k) }\end{array}$ & Cover large drainage area \\
Type II & Low permeability (k) & Good initial production rate \\
Type III & Complex directional permeability (k) & Sustained production \\
Type IV & Negative permeability (k) & Not good \\
\hline
\end{tabular}

permeability whereas type II provides only permeability which is also important for the flow of hydrocarbon. There is no direct contribution of the fracture of type III but it assists the other permeable path in the reservoir.

The presence of natural fractures in the shale gas reservoir is universal. Their presence is the critical factor to estimate a prospective reservoir (Walton and McLennan 2013). A common mechanism of production from shale is to use the naturally fractured network as the formation is severely tight (Carlson and Mercer 1991). The effects of fractures and matrix compressibilities are considered for both saturated and undersaturated reservoirs. Hall (1953) and van der Knaap (1959) modeled some correlation to calculate that compressibility.

Aguilera (1999) used his correlation for the fractured reservoir to estimate the recovery factor based on the different drive mechanisms. However, his model has some challenges and he provided some future guidelines. Most of the naturally fractured reservoirs have low matrix permeability and porosity. For this kind of reservoir, volumetric reserve calculation is a difficult task and hence reserves estimation. The author suggested categorizing this estimation as a possible reserve. Early material
Table 2 Quality of production based on fracture condition (Cherif et al., 2014).

\begin{tabular}{lllll}
\hline Well & $\begin{array}{l}\text { Proximity } \\
\text { of faults }\end{array}$ & $\begin{array}{l}\text { Intensity of } \\
\text { fractures }\end{array}$ & $\begin{array}{l}\text { Type of } \\
\text { fracture }\end{array}$ & $\begin{array}{l}\text { Average } \\
\text { production }\end{array}$ \\
\hline GS-03 & E-W & average & Closed & Bad \\
GS-04 & E-W & strong & Closed & Bad \\
GS-21 & N120 & strong & Partially open & Good \\
GS-08 & E-W & average & Partially open & Bad \\
GS-07 & E-W & strong & Partially open & Bad \\
GS-15 & N120 & strong & Open & Good \\
GS-17 & N120 & strong & Open & Good \\
GS-14 & N120 & strong & Open & Good \\
GS-11 & E-W & average & Partially open & Bad \\
\hline
\end{tabular}

balance calculation provides the probable reserves but with the cumulative production and good pressure data, the reserve should be considered as a possible reserve.

For the unproven reserves, decline curve analysis is a good approach from short reservoir history. However, the decline curve is not suitable for proved reserve unless the well is in the late production stage.

Cherif et al. (2014) published an observation of the relationship between natural fracture and production. They showed how the fracture affects oil production in the unconventional reservoir. Fracture type has also an influence on oil production. Average production from a reservoir depends on not the only intensity of fractures but also on the type of fracture. Table 2 shows that the well GS-04 has a strong intensity of fracture but the average production is bad as the fracture is closed. GS-07 has also a strong fracture but is closed and therefore, the average production is bad. The information from Table 2 proves that there should have a good combination between the intensity of fracture and the type of fracture. Well no GS-14, GS-15, and GS-17 show a good combination. These wells have a strong and open fracture, eventually, these wells have good production.

\subsubsection{Artificial Fractured Formation (Hydraulic Fracturing)}

The United States and Canada have up to 780 TCF and 1100 TCF shale gas reserves respectively (Frantz and Jochen 2005). These possible reserves were produced by the combination of horizontal well technology and hydraulic fracturing. After drilling the horizontal well, fracturing fluids are injected into the well at high pressure to create the fracture, which increases the permeability of the shale zone largely. These fracturing fluids will be recovered immediately after opening the well during a 
post-stimulation 'flow-back'. The flow back data helps significantly to design the fracture model and production forecasting. One of the main natural resources in the world is the shale gas reservoir of Argentina (Duarte et al. 2014). The dual porosity system is available in those reservoirs. The primary porosity is associated with the matrix, and fracture contains the secondary porosity. High matrix porosity but low permeability of the reservoir blocks the movement of the fluids. So, the fracture is very important for smooth permeable ways. In general, the adsorption mechanism works to store the gas to this kind of rock, even sometimes $85 \%$ volume is occupied (Watson 1989).

\subsubsection{Aguilera Approach}

Various authors have been facing huge challenges in the material balance method for years. The effect of fracture compressibility on the gas reservoir has been neglected. Researchers make some assumption for conventional MBE such as: (i) the effects of water influx is negligible, (ii) there is no change in reservoir formation, and (iii) the compressibility of water and formation are neglected. Although these assumptions have no significant effect in some cases, however, there are some cases where the effects are significant (e.g. fracture, compressible rock, etc.). In such a situation, conventional MBE has failed to give a proper estimation of the reserve. These types of challenges are also observed in the geo-pressured reservoir (Aguilera, 2003, and 2004). In the case of storage capacity, fractured reservoirs have much more influence on production engineering. Three types of storage can be identified in this kind of reservoir. Matrix blocks, which is the main storage for hydrocarbon, is denoted by Type $A$. Fracture networks are included with the matrix in Type $B$ storage. The storage capacity of fracture networks is Type C (Aguilera 1995). In a reservoir of Type A, the matrix contains a significant portion of hydrocarbon whereas a very small amount in fractures (McNaughton 1975).

\subsubsection{Naturally Fractured Reservoir}

The Uniform porosity and compressibility assumption of the conventional MBE is no longer valid for naturally fractured reservoirs. The conventional MBE is effectively applicable for Type $A$ and $C$, whereas modified MBE is suitable for Type B (Penuela et al. 2001).

Penuelaet al. (2001) and Sandoval et al. (2009) were proposed some modified models for MBE within the naturally fractured reservoir (NFR). In those models, matrix OHIP and fracture OHIP were shown instead of overall
OHIP. However, some hidden limitations are found in such modifications where matrix and fracture systems were supposed to have an individual effect on reservoir pore volume which is not an accurate assumption for NFR.

For NFR only average pressure and compressibility should be modified which is indicated in Eq. (1). Bashiriet al. (2010) used a more logical modification which was the compressibility and porosity definition to derive the following equation. Gerami et al. (2007) Showeda more simplified formulation of the existing model where effective compressibility of NFR can be reduced.

$$
C_{T}=\frac{\phi_{m}\left(c_{m}+c_{w} S_{w i}\right)+c_{f} \phi_{f}}{\phi_{m}\left(1-S_{w i}\right)+\phi_{f}}
$$

The compressibilities of formation fluid and reservoir rock have a great effect on hydrocarbon production. For calculating the total compressibility of the reservoir, the porosity of the fracture and matrix has an equal role. The majority of the authors incorporated only the porosity of the matrix but avoided the porosity of fracture in their developed model. The porosity of the fracture has been neglected for a long time by the researcher. To characterize the reservoir more accurately, all types of porosities should be considered. Due to the negligence of fracture porosity, hydrocarbon reserve was not properly estimated. Gerami et al. (2007) proved that the total compressibility of the reservoir depends on the porosity of matrix and fracture, the compressibility of a matrix, and fracture and initial water saturation. The right-handed side of equation 6 has fracture porosity as a denominator. If this porosity is not considered in the above equation, the total compressibility will be increased which finally will affect the reserve estimation.

\subsection{Dynamic Material Balance Equation}

The dynamic material balance (DMB) is an additional feature of the flowing material balance equation and this equation applies to both constant and variable flow rates. Both the flowing material balance method and $D M B$ method are suitable for the oil and gas reservoir. DMB is nothing but a systematic way that alters the flowing pressure at any point to the average reservoir pressure. Once the average reservoir pressure is calculated, the classical material balance method becomes eligible to apply and then the traditional $\mathrm{P} / \mathrm{Z}$ vs $\mathrm{Gp}$ plots are generated. Although the author effectively described the procedure, still there are some common limitations like others. Unable to treat transient flow data is one of the 
major limitations of this method. Pressure-dependent permeability and variable skin factor have not been considered during the development of the equation (Mattar et al. 2006).

DMB is also an effective method to determine the initial gas-oil ratio $(m)$, initial-oil-in-place $(N)$, reservoir permeability $(\mathrm{K})$, skin factor $(\mathrm{S})$, and average pressure decline history. An estimation of the original-oil-in-place (OOIP) and the determination of average pressure decline history can be obtained through the inclusion of timevariable into the classical MBE. Average pressure decline history directly helps to calculate reservoir permeability and skin factor. The model was developed by assuming no flow existence in the bounded reservoir. This dynamic method has been developed based on a visual basic program (Ojo et al. 2003).

\subsection{Time-Dependent MBE}

Huge research works on $\mathrm{MBE}$ have been conducted for the last five decades (Havlena and Odeh 1963; Havlena and Odeh 1964; Ramagost and Farshad, 1981; Fetkovich et al. 1991; Fetkovich et al.1998; Rahman et al. 2006a). All these previous researchers developed MBE for the gas reservoir by using an expansion drive mechanism. Hossain et al. (2009) incorporated time-dependent rock/fluid properties into the previous model. Expansion of oil, water, rock, and dissolved gas is included in their model. In addition, the authors incorporated the time-dependent rock/fluid properties which are named as memory function. This concept is defined as "the properties of rock and fluid that help to account for changes in rock properties (such as permeability and porosity) and fluid properties (such as pressure-dependent fluid properties and viscosity) with time and space" (Hossain 2016). Besides, a simple definition of memory concept is also proposed by Hossain (2016) as "the system can remember its previous state".

According to Doe (1983), "The past is the key to the future". Irrespective of the research area, a variety of studies are going on to know about the future. With technological advancement, these future-predicting studies are going to be easier. Scientists or researchers are now predicting the future trend of the respective field with more accuracy. But one exclusive way to predict the future is the study of the past what is known as memory.

Predicting future geologic trends through the study of past events has been initiated in the 1970s. The geologic prediction has been established through three major lines.
These are climate change, element migration, and neotectonics (Doe 1983).

In the fundamental sense, the thinking ability of mankind and animal is known as memory. In recent times, scientists have included nonliving things into the definition of memory. A computer has also memory which is called storage. This type of memory is also known as indirect signal memory. Rock also has a memory that includes longterm history memory, behavior- reproducing memory, and stress memory. The main theme of stress memory of rock is: "every preceding step of excavation must give effects to all of the subsequent steps; i.e., rocks can remember all of the stresses they underwent in the past" (Xuefu et al., 1995). For example, $y=x^{3}, \frac{d y}{d x}=3 x^{2} ; y^{1}=3 x^{2} ; y^{2}=6 x$. In the derivative, the order is an integer. What will happen if the order is a fraction such as $1 / 2$ ? To answerthe engineering aspect, Du et al. (2013) published an article on "measuring memory with the order of fractional derivative." In their observation, there are two stages of the memory process. One is a fresh stage and another one is the working stage. Fractional derivative is an index of memory. That's why the order with integer numbers cannot give the proper idea of memory. The critical point between the fresh stage and the working stage is needed to be considered to get an accurate index of memory.

As a result, the researcher should consider the system's previous history for the future forecast of the outcome. Table 3 shows how the time variable is considered in different disciplines. Du et al. (2013) researched mechanics and he successfully incorporated the time variable as a fractional derivative in his works. He showed that there must be a change of properties after the change of gradient within a time interval. Xuefu et al. (1995) used the time variable in his works as a memory term where he explained that every previous step of excavation will give the effect to immediate step. Bruce (1983) conducted good research on time factors for the geological change and he summarized that the past explains what will happen next which we can designate as memory in our current subject research.

\subsubsection{Hossain et al. Approach}

Hossain et al. (2009) developed a generalized MBE based on the expansion drive mechanism to explore the effect. They introduced a new dimensionless parameter, $C_{\text {epm }}$ to illustrate the whole expansion drive mechanism which is written as: 
Table 3 A summary of some research on the time factor.

\begin{tabular}{|c|c|c|c|c|}
\hline Researcher & \multicolumn{2}{|l|}{ Field of research } & Considered terminology & Theme of the research \\
\hline Hassan et al. (2016) & \multicolumn{2}{|l|}{ Reservoir engineering } & $\begin{array}{l}\text { Memory-based fluid viscosity, } \\
\text { velocity, and pseudo-permeability }\end{array}$ & $\begin{array}{l}\text { Reservoir rock and fluid properties affect the pressure } \\
\text { response with the effect of memory }\end{array}$ \\
\hline Du et al. (2013) & \multicolumn{2}{|l|}{ Mechanics } & $\begin{array}{l}\text { Fractional derivative (Continuous- } \\
\text { time function) }\end{array}$ & $\begin{array}{l}\text { The change of a property after change of gradient of that } \\
\text { property within a time interval }\end{array}$ \\
\hline \multirow{2}{*}{ Hossain et al. (2009) } & Reservoir Engineering & Enhanced oil recovery (EOR) & \multirow{2}{*}{$\begin{array}{l}\text { Time-dependent permeability } \\
\text { and viscosity }\end{array}$} & \multirow{2}{*}{$\begin{array}{l}\text { Diminution of permeability with time due to the reduction of } \\
\text { pore size }\end{array}$} \\
\hline & Chemical Engineering & Polymer Manufacturing & & \\
\hline Hossain et al. (2008a) & Reservoir engineering & $\begin{array}{l}\text { Fluid flow through porous } \\
\text { media }\end{array}$ & $\begin{array}{l}\text { Memory } \\
\text { (time and space) }\end{array}$ & $\begin{array}{l}\text { During the geothermal action and chemical reactions in the } \\
\text { reservoir, permeability and viscosity act as a time-dependent } \\
\text { parameter }\end{array}$ \\
\hline Xuefuet al. (1995) & \multicolumn{2}{|l|}{ Rock mechanics } & Memory & $\begin{array}{l}\text { Every previous step of excavation will give the effect to } \\
\text { immediate step }\end{array}$ \\
\hline Doe (1983) & \multicolumn{2}{|l|}{ Geology } & Memory & The past explains what will happen next \\
\hline Caputo (1999) & \multicolumn{2}{|l|}{ Geothermic } & Time-dependent permeability & effect of decreasing permeability with a memory formalism \\
\hline Caputo (2000) & \multicolumn{2}{|l|}{ Water resource } & $\begin{array}{l}\text { Pressure and density variations } \\
\text { with memory formalism }\end{array}$ & $\begin{array}{l}\text { Permeability varies with time when there is a change of } \\
\text { pressure gradient and flow }\end{array}$ \\
\hline Hossainet al. (2008c) & \multicolumn{2}{|l|}{$\begin{array}{l}\text { Reservoir engineering } \\
\text { (EOR; Thermal recovery) }\end{array}$} & $\begin{array}{l}\text { Temperature variation with the } \\
\text { change of time and distance }\end{array}$ & $\begin{array}{l}\text { Time, formation of fluid velocity, and steam injection velocity } \\
\text { play a vital role in temperature profile behavior. }\end{array}$ \\
\hline
\end{tabular}

$C_{e p m}=\frac{S_{o i} C_{o}+S_{w i} C_{w}+S_{g i} C_{g}\left(\frac{R_{s o i}}{B_{o i}}+\frac{R_{s w i}}{B_{w i}}\right) B_{g i}+C_{s}+M\left(C_{w}+C_{s}\right)}{1-S_{w i}} \Delta p$

Equation (7) is applicable when the average reservoir pressure is considered.

A dimensionless term, $C_{\text {epm }}$ in the above equation, can be counted as an important energy source for the production of oil in an expansion drive. Compressible residual fluids and expansion of rock are the two main drivers for their model equation. Referring to other researchers, the value of $C_{e p m}$ is not considered only as oil/gas compressibilities (Dake 1978; Fetkovich et al. 1991; Fetkovich et al. 1998; Ahmed 2000; Rahman et al. 2006b), rather $C_{\text {epm }}$ is the function of present reservoir pressure, compressibilities, initial saturation, dissolved gas properties and associated volume fraction.

\subsubsection{Buduka et al. Approach}

The straight-line model of Havlena and Odeh is based on the existing reservoir drive. Estimation of initial-oil-in-place and cumulative oil produced by Havlena and Odeh method does not consider the time function of the average production of the field life. Buduka et al. (2015) presented an alternative Havlena and Odeh method in which underground recoverable functions $F$ are plotted against oil plus gas expansion function $E$ per cumulative time so that reservoir engineers can get the updated information each time limit. Warner et al. (1979) identified that, though the material balance method is used as a pre- processing tool to estimate the hydrocarbon-in-place, it still has some limitations.

\subsubsection{Introduction of Time dimension}

By using Havlena and Odeh's model for general MBE, Buduka et al. (2015) introduced an alternative time function model. They defined all the terms in general MBE by incorporating the time function. They developed a model where a plot was constructed on the average production rate of reservoir vs. cumulative production. The time was set as an independent variable.

$$
N_{p}=\sum_{k=1}^{n} Q_{k} t_{k}
$$

$\mathrm{k}$ represents the time at the point of each reservoir average pressure and the total point of average pressure is n. Anderson and Mattar (2003) showed that the time function is mandatory to convert the general production condition into an equivalent constant rate solution. The time is a superposition function when the depletion is volumetric. For the bounded flow regime, the material balance with time function provides an exact conversion of constant pressure data to type curves of a constant rate (Blasingame et al. 1991, and Agarwal et al. 1998). Poe (2002) showed the usefulness of using a material balance with a time variable for the transient flow regime. Therefore, time-dependent MBE is needed to characterize the rock/fluid alteration during the production life of the reservoir in addition to get a reliable reserve estimate. 
Table 4 Some recent research summary on the material balance method.

\begin{tabular}{|c|c|c|c|c|}
\hline Authors & Assumptions & Findings & Limitations & $\begin{array}{l}\text { Inclusion of water } \\
\text { influx, (We) }\end{array}$ \\
\hline Cabrapan et al. (2014) & Presence of dual porosity & Additional way to estimate OGIP & $\begin{array}{l}\text { No incorporation of water } \\
\text { influx (We) }\end{array}$ & $x$ \\
\hline Ismadi et al. (2011) & $\begin{array}{l}\text { Homogeneous reservoir with } \\
\text { radial geometry }\end{array}$ & Combined static and dynamic method & $\begin{array}{l}\text { Different conditions of the } \\
\text { reservoir are missing }\end{array}$ & $x$ \\
\hline Sandoval et al. (2009) & $\begin{array}{l}\text { Existence of four faces: oil, } \\
\text { water, gas and naturally } \\
\text { fractured rock }\end{array}$ & $\begin{array}{l}\text { Calculate IOIP for fracture containing } \\
\text { saturated and under-saturated } \\
\text { reservoir }\end{array}$ & $\begin{array}{l}\text { Some critical assumptions } \\
\text { were made. } \\
\text { e.g. } \frac{d \phi_{f}}{d r}=0\end{array}$ & $x$ \\
\hline Peron et al. (2007) & Tri- phase flow & $\begin{array}{l}\text { Contribution of matrix to the } \\
\text { production }\end{array}$ & $\begin{array}{l}\text { Applicable only for high } \\
\text { permeability fractures }\end{array}$ & $x$ \\
\hline Penuelaet al. (2001) & $\begin{array}{l}\text { instantaneous flow of } \\
\text { hydrocarbons from the } \\
\text { matrix to the fracture media. }\end{array}$ & $\begin{array}{l}\text { Simultaneous estimation of oil stored } \\
\text { both in the matrix and fracture }\end{array}$ & $\frac{d \phi_{f}}{d r}=0$ & $\checkmark$ \\
\hline
\end{tabular}

\section{Critical Analysis}

After a long review of the existing work on the material balance method, some critical analyses should be provided. All the researchers tried to develop a model with more accuracy. The reviewed article proves that maximum effort in terms of knowledge and experiment was delivered to develop these innovative models. As a beginner in the research area, it is difficult and challenging to analyze the established work critically. However, a small attempt should be taken to improve the research skill. In most cases, single porosity is considered instead of dual porosity. Cabrapan et al. (2014) developed a model to estimate original-gas-in-place where he assumed the presence of dual porosity. Thus, he got a better estimation of hydrocarbon for a specific field. But on the contrary, the author didn't incorporate the water influx which affects the production badly. So, this is a scope to conduct further research where an MBE model will be developed with the inclusion of dual-porosity and water influx. In Table 4, only five authors are included were four of them neglected the inclusion of water influx in their research. Some critical review is shown in Table 4.

To increase the scope of further research, a critical review was conducted in terms of the considered parameter. Ibrahim et al. (2013) developed an MBE where he considered separator conditions. Singh (2013) incorporated the desorption term, Gd in his model. Penuela et al. (2001) added the net expansion of the matrix, Eo1, and net expansion of the fracture, Eo2. Table 5 shows a summary of some works based on the considered parameter. Pennuela (1998) considered dualporosity in his developed model where he considered the secondary porosity. It is already stated that most of the authors avoided the formation of compressibility in their developed model. Ambastha (1990a and 1990b) followed another approach to reduce the error created by neglected compressibility. He used a correction factor in his model to increase accuracy. Table 5 also shows that, some important parameters which are neglected by some researcher although some of them incorporated those parameters. For instance, Nader (1964) developed a model on two-phase reservoirs, where he incorporated the gas formation volume factor but didn't consider the parameter water influx and solution gas-oil ratio. This table also shows the development of some models with the inclusion of special parameters.

One of the most important purposes of this review is to establish a theoretical framework for my new model development. Therefore, this review has been critically reviewed different articles in terms of dynamism, applicability, and limitations. Istayeva and King (2014) developed a dynamic material balance equation (DMBE) for the conventional reservoir. This equation appliesto preand post-well operations. However, this model is suitable only for the carbonate reservoir. The model may be extended to develop a model for sandstone and limestone reservoir. Ismadi et al. (2011) offered a static and dynamic model for the conventional reservoir which is applicable for layered system reservoirs. He followed the pseudosteady state approach to develop his model. He considered that the reservoir is homogeneous and the shape of the reservoir is radial. So far it very rare to find a truly radial shape reservoir. Many of the reservoirs have an irregular shape. To overcome this limitation, a new DMBE can further be developed for the irregularly shaped reservoir. 
Table 5 A comparative study on the developed model for material balance equation

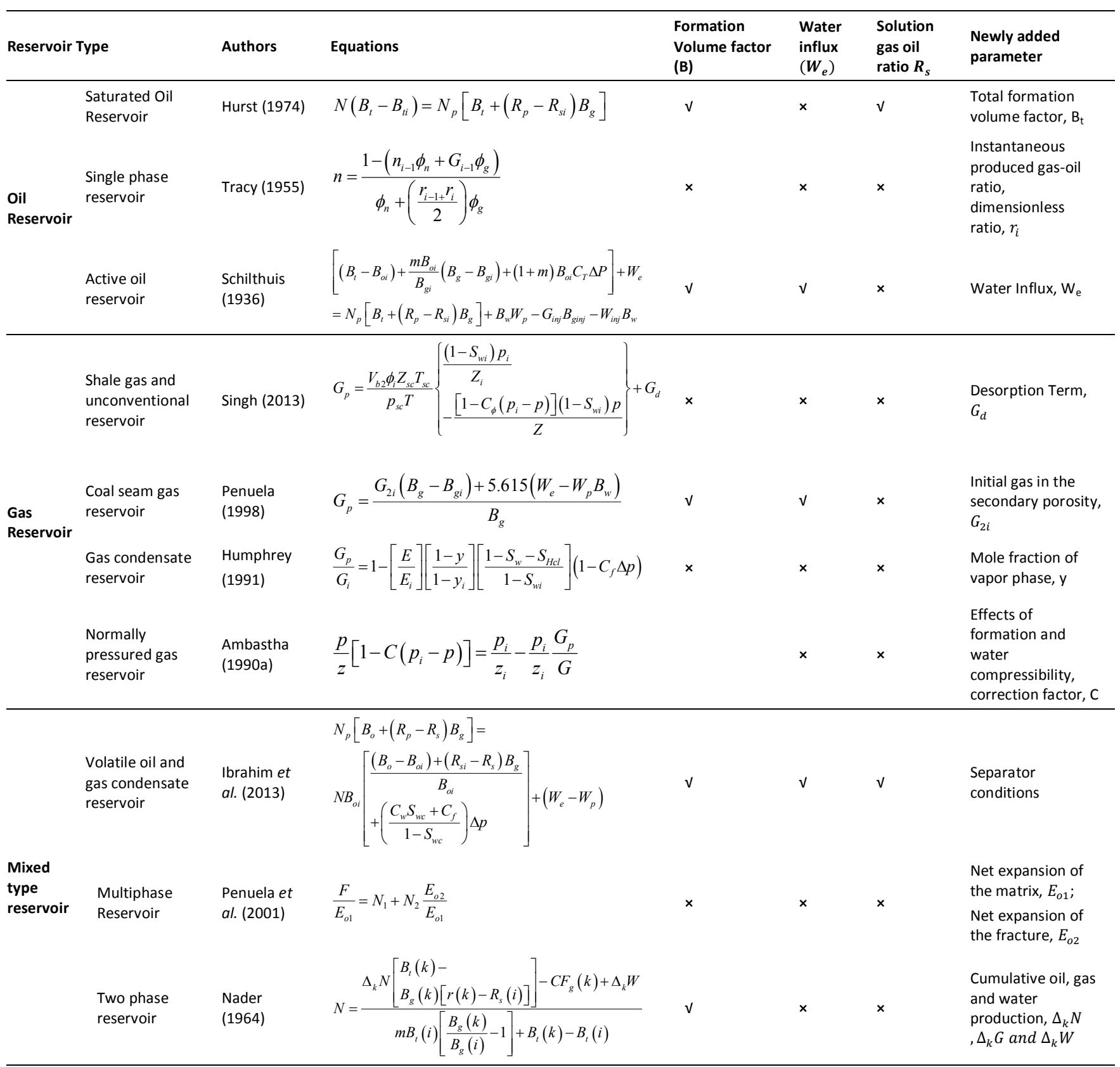

A summary of previous works on the dynamic material balance method is given in Table 6 .

\section{Research Challenges and Guidelines}

The material balance method is the basis for analyzing reserve estimation as well as reservoir performance. The combination of mass balance and energy balance is the governing equation for the material balance technique. To develop a rigorous $\mathrm{MBE}$, some simplified assumptions are considered such as the reservoir is assumed to be homogeneous and isotropic, rock compressibility is assumed to be negligible, and the flow-through porous media are considered as a steady-state. These unsound assumptions will lead to a result of less accurate when reservoir properties are implemented in field conditions. Disregarding the time factor in the equation is one of the most vital causes of increasing the error of the result.

Based on the conducted research, now it is clear that almost all the reservoir properties are time-dependent. There is a significant alteration of these reservoir properties while it changes with time due to production, in-situ stresses, mineralization, precipitation, etc. Therefore, there is a need to incorporate a time dimension during the development of a DMBE. 
Table 6 A summary of some important works based on dynamism, applicability, and limitations.

\begin{tabular}{|c|c|c|c|c|}
\hline Authors & $\begin{array}{l}\text { Dynamic/ } \\
\text { static }\end{array}$ & $\begin{array}{l}\text { Reservoir } \\
\text { type }\end{array}$ & Application & Limitations \\
\hline Istayeva and King (2014) & Dynamic & Conventional & Applicable for pre-and post-well operations. & Only suitable for carbonate reservoir \\
\hline Ismadi et. al (2011) & $\begin{array}{l}\text { Static and } \\
\text { dynamic }\end{array}$ & Conventional & $\begin{array}{l}\text { Applicable for layered system reservoir, pseudo- } \\
\text { steady state approach }\end{array}$ & $\begin{array}{l}\text { Homogeneous reservoir with radial } \\
\text { geometry }\end{array}$ \\
\hline Ojo et. al (2006) & Dynamic & Conventional & $\begin{array}{l}\text { Applicable for saturated and primarily depleted } \\
\text { reservoir }\end{array}$ & $\begin{array}{l}\text { No guideline for fractured reservoir } \\
\text { are suggested }\end{array}$ \\
\hline Mattar et. al (2006) & Dynamic & Conventional & $\begin{array}{l}\text { Applicable for either } q=\text { constant or variable } \\
\text { flow rate. } P_{r} \text { can be obtained without shut in the } \\
\text { production }\end{array}$ & $\begin{array}{l}\text { Fractured conditions of the reservoir } \\
\text { are not considered }\end{array}$ \\
\hline Tian and Zhao (2004) & Static & Conventional & $\mathrm{N} / \mathrm{A}$ & $\begin{array}{l}\text { 1. Phase equilibrium throughout the } \\
\text { reservoir } \\
\text { 2. } \bar{T}_{\text {res }}=\text { constant }\end{array}$ \\
\hline Ojo et. al (2004) & Dynamic & Conventional & Applicable even with limited pressure data & Visual basic based program was used \\
\hline Ambastha (1990b) & Static & Conventional & $\begin{array}{l}\text { 1. Applicable for normally pressured gas reservoir } \\
\text { 2. also for abnormally pressured gas reservoir }\end{array}$ & $\begin{array}{l}G_{p} \text { graph due to the pressure squared } \\
\operatorname{term}\left(p^{2} / z\right)\end{array}$ \\
\hline & & & & 2. Not applicable for oil reservoir \\
\hline $\begin{array}{l}\text { Miranda and Raghavan } \\
\text { (1975) }\end{array}$ & Static & Conventional & $\begin{array}{l}\text { 1. for determining oil in place and } \\
\text { 2. the ratio of gas cap to oil column volume }\end{array}$ & Not suitable water drive reservoir \\
\hline Hurst (1974) & Static & Conventional & $\begin{array}{l}\text { Developed a relationship between oil saturation in } \\
\text { place versus reservoir pressure. }\end{array}$ & Insensitive to establish OIP \\
\hline Tracy (1955) & Static & conventional & Determination of instantaneous GOR & Unreliable OIP in early life of a reservoir \\
\hline
\end{tabular}

One of the important challenges for the shale gas reservoir is that the production mechanism is affected by the condensation. Artificial fracturing and gas injection may decrease this effect and improve performance. Low pressure is the most challenge for a saturated oil reservoir. Sufficient PVT and viscosity data can be used to overcome this challenge. Sometimes, in the dry gas reservoir, getting flowing bottom-hole data is a troublesome issue. In such a case, all types of data consideration would be a good solution.

Sometimes, $\mathrm{CO}_{2}$ is injected in the depleted reservoir to get a driving force for production. However, other impurities with injected $\mathrm{CO}_{2}$ create a major problem during production. The production engineer should be very careful during the injection. However, $\mathrm{H}_{2} \mathrm{O}$ is another choice in this regard. There are lots of multilayered reservoirs in the world. These multilayered reservoirs have different skin factor for each layer. This skin factor affects the response of pressure build-up. Multi-rate testing is a good solution for this situation. Some other challenges and guidelines are reported in Table 7.

\section{Conclusion}

The comprehensive literature review provides that a plethora of research works were conducted on thematerial balance method for both conventional and unconventional reservoirs. In these studies, many mathematical models were developed to estimate hydrocarbon reserves. Most of those models were developed based on some assumptions which don't reflect the real behavior of the reservoir. The MBE cannot be used in prospective reserve estimations if the reservoir shows unconventional circumstances. The considered assumptions restrict the extensive use of the model.

This analysis shows that in almost every work, few parameters are incorporated to develop a model. For instance, the continuous alteration of rock and fluid properties is ignored during the model development for the fractured reservoir. Without considering the time variable, the model of the material balance method cannot estimate the prospective reserve accurately. For example, in much of the study, the porosity and permeability of the reservoir were considered uniform throughout. However, as porosity and permeability are the parameters that change with time, the reserve predictions are no longer effective, and accurate. The dual porosity of the reservoir was also ignored in some research on the fractured reservoir. Considering single porosity instead of dualporosity will not give a reliable result on a reserve estimation. Without a proper estimation of the reserve, 
Table 7 Some guidelines are based on current challenges.

\begin{tabular}{|c|c|c|c|c|}
\hline $\begin{array}{l}\text { MBE for different } \\
\text { reservoir conditions }\end{array}$ & Author & Current development & Challenges & Guidelines \\
\hline Shale gas reservoir & $\begin{array}{l}\text { Orozco and } \\
\text { Aguilera } \\
(2017)\end{array}$ & $\begin{array}{l}\text { Method of estimating } \\
\text { OGIP and OCIP }\end{array}$ & $\begin{array}{l}\text { Production mechanism affected } \\
\text { by condensation }\end{array}$ & $\begin{array}{l}\text { Artificial fracturing and gas injection are needed } \\
\text { to improve the performance of this method }\end{array}$ \\
\hline $\begin{array}{l}\text { Saturated oil } \\
\text { reservoir }\end{array}$ & $\begin{array}{l}\text { Mosobalajeet } \\
\text { al. (2015) }\end{array}$ & $\begin{array}{l}\text { A material balance } \\
\text { equation for } \\
\text { multiphase flow }\end{array}$ & $\begin{array}{l}\text { Approximation of gas oil ratio } \\
\left(R_{p}\right) \text { and low pressure }\end{array}$ & $\begin{array}{l}\text { Accuracy of PVT and viscosity data should be } \\
\text { increased }\end{array}$ \\
\hline Dry gas reservoir & $\begin{array}{l}\text { Guzman et al. } \\
(2014)\end{array}$ & $\begin{array}{l}\text { Flowing gas material } \\
\text { balance equation }\end{array}$ & Insufficient flowing data & $\begin{array}{l}\text { Controllable and uncontrollable flow data are } \\
\text { needed to consider }\end{array}$ \\
\hline $\begin{array}{l}\text { Depleted gas } \\
\text { reservoir }\end{array}$ & $\begin{array}{l}\text { Lawal and } \\
\text { Frailey (2004) }\end{array}$ & $\begin{array}{l}\text { A material balance } \\
\text { equation with } \mathrm{CO}_{2} \\
\text { sequestration }\end{array}$ & Impurities in injected $\mathrm{CO}_{2}$ & Monitoring reservoir and $\mathrm{CO}_{2}$ during injection \\
\hline Tight gas reservoir & $\begin{array}{l}\text { Kuppeet al. } \\
\text { (2000) }\end{array}$ & $\begin{array}{l}\text { - Layered material } \\
\text { balance equation } \\
\text { - A diagnostic tool to } \\
\text { determine OGIP }\end{array}$ & $\begin{array}{l}\text { - Water influx are not considered } \\
\text { - The pressure buildup response } \\
\text { is affected by layer skin factor }\end{array}$ & $\begin{array}{l}\text { - Multi-rate tests may be conducted to verify } \\
\text { layering } \\
\text { - Advanced decline curve analyzed should be } \\
\text { used }\end{array}$ \\
\hline $\begin{array}{l}\text { Over-pressured gas } \\
\text { reservoir }\end{array}$ & $\begin{array}{l}\text { Wang et al. } \\
\text { (1999) }\end{array}$ & $\begin{array}{l}\text { Method of detecting } \\
\text { aquifer influence, } \\
\text { water influx and OGIP }\end{array}$ & $\begin{array}{l}\text { The availability of laboratory } \\
\text { measured fluid compressibility } \\
\left(C_{f}\right)\end{array}$ & $\begin{array}{l}C_{f} \text {, in the order of } 10^{-5} 1 / p s i \text { suggested avoiding } \\
\text { overestimation }\end{array}$ \\
\hline $\begin{array}{l}\text { Under-pressured } \\
\text { gas reservoir }\end{array}$ & Wang (1998) & $\begin{array}{l}\text { A method of MBE for } \\
\text { normal and abnormal } \\
\text { pressure gradient }\end{array}$ & Absence of aquifer & Water injection may give a good estimation \\
\hline $\begin{array}{l}\text { Water drive } \\
\text { reservoir }\end{array}$ & Sills (1996) & $\begin{array}{l}\text { Water drive material } \\
\text { balance with using } \\
\text { CARET }\end{array}$ & Constant water influx & Variable aquifer compressibility may be added \\
\hline $\begin{array}{l}\text { Undersaturated oil } \\
\text { reservoir }\end{array}$ & Barry (1963) & $\begin{array}{l}\text { A modification of } \\
\text { standard MBE for the } \\
\text { reservoir of above } \\
\text { bubble point pressure. }\end{array}$ & $\begin{array}{l}\text { Consideration of circular } \\
\text { reservoir }\end{array}$ & $\begin{array}{l}\text { Should be applied to some other field to justify } \\
\text { the result }\end{array}$ \\
\hline
\end{tabular}

the feasibility study of production will be interrupted and the economic viability of the project will be questionable. This critical review will help to understand how to modify the current MBEs for different reservoir types including unconventional reservoirs. In addition, this research will help to guide the development of DMBE. In such a case, the developed model can be applied for all the discussed conditions to accurately estimate the reserves of unconventional reservoirs too.

\section{Disclosures}

Free Access to this article is sponsored by EURL BADYLEC.

\section{Acknowledgments}

The authors would like to thank the Natural Sciences and Engineering Research Council of Canada (NSERC); Research \& Development Corporation of Newfoundland and Labrador (RDC), funding no. 210992; and Statoil Canada Ltd., funding no. 211162 for providing financial support to accomplish this research under the Statoil Chair in
Reservoir Engineering at the Memorial University of Newfoundland, St. John's, NL, Canada.

\section{Nomenclature}

$\Delta_{k} G \quad$ Cumulative gas production, scf

$\Delta_{k} N \quad$ Cumulative oil production, stb

$\Delta_{k} W \quad$ Cumulative water production, stb

$\rho_{b} \quad$ Bulk density, $\mathrm{g} / \mathrm{cm}^{3}$

$B_{g} \quad$ Gas formation volume factor, $r b / s c f$

$B_{g f} \quad$ Gas formation volume factor for Fracture, $r b / s c f$

$B_{g i} \quad$ Bg at initial reservoir pressure, $r b / s c f$

$B_{g m} \quad$ Gas formation volume factor for matrix, $r b / s c f$

$B_{o} \quad$ Oil formation volume factor, $r b / s t b$

$B_{\text {of }} \quad$ Oil formation volume factor for fracture, $r b / s t b$

$B_{o i} \quad$ Initial oil formation volume factor, $b / s t b$

$B_{o m} \quad$ Oil formation volume factor for matrix, $r b / s t b$

$B_{t} \quad$ Total formation volume factor, $r b / s t b$

$B_{t i} \quad \mathrm{~B}_{\mathrm{t}}$ at initial reservoir pressure, $r b / s t b$

$B_{w} \quad$ Water formation volume factor, $r b / s t b$

$B_{w i} \quad \mathrm{~B}_{\mathrm{w}}$ at initial reservoir condition, $b \mathrm{bl} / \mathrm{stb}$

$B_{w m} \quad$ Water formation volume factor for matrix

$C_{\text {epm }}^{\prime}$ Modified dimensionless parameter

$C_{T} \quad$ Total compressibility, $\mathrm{psi}^{-1}$ 
$C_{\text {epm }}$ Parameter of effective compressibility due to residual fluid, dissolved gas and formation for the proposed MBE, dimensionless

$C_{f} \quad$ Rock compressibility, psi $^{-1}$

$c_{f} \quad$ Average fracture compressibility, $\mathrm{psi}^{-1}$

$C_{g} \quad$ Gas compressibility, $\mathrm{psi}^{-1}$

$C_{m} \quad$ Matrix compressibility, $\mathrm{psi}^{-1}$

$c_{m} \quad$ Average matrix compressibility, $\mathrm{psi}^{-1}$

$c_{S} \quad$ Reservoir rock formation compressibility at a reduced pressure $\mathrm{p}, \mathrm{psi}^{-1}$

$C_{o} \quad$ Oil compressibility, $\mathrm{psi}^{-1}$

$C_{\text {rock }}$ Rock compressibility, $\mathrm{psi}^{-1}$

$C_{w} \quad$ Water compressibility, $\mathrm{psi}^{-1}$

$C_{w} \quad$ Water compressibility, $\mathrm{psi}^{-1}$

$C_{\varphi} \quad$ Pore compressibility, $\mathrm{psi}^{-1}$

$E_{i} \quad$ Initial expansion, RB/STB

$E_{o 1} \quad$ Net expansion of the original oil-phase in the matrix system, RB/STB

$E_{O 2} \quad$ Net expansion of the original oil-phase in the fracture network, RB/STB

$G_{2 i} \quad$ Initial gas in the secondary-porosity, scf

$G_{i} \quad$ Initial gas in the reservoir, scf

$G_{\text {inj }}$ Cumulative gas injection, $\mathrm{m}^{3}$

$G_{p} \quad$ Produced wellhead gas, $s c f$

$G_{t} \quad$ Total produced gas, scf

$M_{\alpha} \quad$ Marangoni number

$N_{1} \quad$ Original oil-in-place in the rock matrix, stb

$N_{2} \quad$ Original oil in-place in the fractures, stb

$N_{p} \quad$ Cumulative produced oil, stb

$P_{L} \quad$ Liquid pressure, psi

$P_{i} \quad$ Initial pressure, psi

$Q_{k} \quad$ Cumulative production at average pressure point time,

$R_{p} \quad$ Cumulative gas oil ratio

$R_{s f} \quad$ Solution gas oil ration in fracture

$R_{s i} \quad$ Initial solution gas-oil ratio

$R_{s m} \quad$ Solution gas-oil ratio in matrix

$R_{\text {soi }} \quad$ Initial solution gas-oil ratio

$R_{\text {Swi }} \quad$ Initial solution oil-water ratio

$S_{\mathrm{HCl}} \quad$ Saturation of $\mathrm{HCl}$

$S_{g i} \quad$ Initial gas saturation

$S_{o i} \quad$ Initial oil saturation

$S_{w f} \quad$ Final water saturation

$S_{w i} \quad$ Initial water saturation

$S_{w m} \quad$ Water saturation in matrix

$T_{T} \quad$ Tank temperature, ${ }^{\circ} \mathrm{R}$

$T_{s c} \quad$ Temperature in standard condition, ${ }^{\circ} \mathrm{R}$

$V_{L} \quad$ Liquid volume, bbl

$V_{b 2} \quad$ Bulk volume of secondary layer, $\mathrm{ft}^{3}$

$W_{e} \quad$ Water influx (encroachment), cumulative, bbl

$W_{\text {inj }} \quad$ Water injected, cumulative, $\mathrm{cm}^{3}$

$W_{p} \quad$ Water produced, cumulative, $\mathrm{cm}^{3}$

$Z_{c} \quad$ Critical compressibility factor
$Z_{i} \quad$ Initial gas compressibility factor

$Z_{s c} \quad$ Gas compressibility factor in standard condition

$\frac{d u_{x}}{d_{y}} \quad$ Velocity gradient along $y$-direction, $1 / \mathrm{s}$

$r_{i} \quad$ Inner radius of well, $\mathrm{ft}$

$t_{k} \quad$ Time at average pressure point time, hrs

$w_{f} \quad$ Fluid influx, bbl

$y_{i} \quad$ Initial mole fraction

$\alpha_{D} \quad$ Thermal diffusivity, $\mathrm{ft}^{2} / \mathrm{s}$

$\mu_{o} \quad$ Oil viscosity, $\mathrm{cp}$

$\tau_{T} \quad$ Shear stress at temperature $\mathrm{T}, \mathrm{Pa}$

$\phi_{g} \quad$ Porosity of fracture

$\phi_{g} \quad$ Granular porosity

$\phi_{i} \quad$ Initial porosity

$\phi_{m} \quad$ Porosity of matrix

$\phi_{n} \quad$ Noneffective porosity

$\omega_{a} \quad$ Fraction of the original gas in place

$\omega_{m} \quad$ Fraction of original gas in place in matrix

$\Delta P \quad$ Pressure difference, $\mathrm{psi}$

$\Delta T \quad$ Temperature difference

$C^{\prime} \quad$ Effective matrix compressibility, 1/psi

$C^{\prime \prime} \quad$ Effective fracture compressibility, 1/psi

$E \quad$ Net expansion function

$F \quad$ Underground recoverable function

$K \quad$ Reservoir Permeability, $\mathrm{mD}$

$M \quad$ Molecular weight, $\mathrm{g} / \mathrm{mol}$

$P \quad$ Reservoir pressure, psi

$P(t) \quad$ Pressure as a function of time, psi

$R \quad$ Gas-law constant, J/ (g mol-K)

$Z \quad$ Gas deviation factor

$m$ Ratio of initial reservoir free-gas volume to initial reservoir oil volume

$r(k)$ Radius of reservoir as a function of permeability, $\mathrm{ft}$

$y \quad$ Mole fraction

$\Gamma \quad$ Gamma function

$\alpha \quad$ Fractional-order of differentiation, dimensionless

$\eta \quad$ Ratio of the pseudo permeability of the medium with memory to fluid viscosity, $\mathrm{ft}^{3} S^{1+\alpha} / \mathrm{lbm}$

$\xi \quad$ A dummy variable for time i.e. real part in the plane of the integral, $s$

$\omega \quad$ Fraction of original gas in place

\section{References}

Agbodike, B., Osokogwu, U., \&Achumba, G. (2019, August 5). Solution to Limited Pressure BHP Data in Brown Fields; Material Balance Equation Approach. Society of Petroleum Engineers. doi :10.2118/198785-MS

Agarwal, R.G, Gardner, D.C, Kleinsteiber, S.W, and Fussell, D.D. : "Analyzing Well Production Data Using Combined Type Curve and Decline Curve Concepts," paper SPE 57916 presented at the 1998 SPE Annual Technical Conference and Exhibition, New Orleans, 27-30 September. 
Aguilera, R. (2003, January 1). Effect of Fracture Compressibility on Oil Recovery from Stress-Sensitive Naturally Fractured Reservoirs. Petroleum Society of Canada.

Aguilera, R. (2004, January 1). Effect of Naturally Fractured Aquifers on Oil Recovery from Stress-Sensitive Naturally Fractured Reservoirs. Petroleum Society of Canada. doi $: 10.2118 / 2004-111$.

Aguilera, R. (2006, December 1). Effect of Fracture Compressibility on Oil Recovery from Stress-Sensitive Naturally Fractured Reservoirs. Petroleum Society of Canada. Vol. 45, No. 12 :49-59.

Aguilera, R. (2008, April 1). Effect of Fracture Compressibility on Gas-in-Place Calculations of Stress-Sensitive Naturally Fractured Reservoirs. Society of Petroleum Engineers.

Aguilera, R., \& Lopez, B. (2013, August 20). Evaluation of Quintuple Porosity in Shale Petroleum Reservoirs. Society of Petroleum Engineers. doi :10.2118/165681-MS.

Aguilera, R., 1995. Naturally Fractured Reservoir, Pennwell Books, Oklahoma, USA, 521 pp.

Aguilera, R., Recovery Factors and Reserves in Naturally Fractured Reservoirs; Journal of Canadian Petroleum Technology, Vol. 38, pp. 15-18, July 1999.

Ahmed, T., Paul D. McKinney, 2005. Advanced Reservoir Engineering, Gulf Professional Publishing, 442 pp.

Sharif, A. (2007) Tight gas resources in Western Australia. Western Australia Department of Mines and Petroleum, Sept. 2007, 28-31.

Ambastha, A. K. (1990) Analysis of material balance equations for gas reservoirs. In Annual Technical Meeting. Petroleum Society of Canada.

Amyx, J.W., Bass, D.M. and Whiting, R.L.:Petroleum Reservoir Engineering - Physical Properties. McGraw-Hill,New York (1960).

Anderson, D. M., \&Mattar, L. (2003, January 1). Material-BalanceTime during Linear and Radial Flow. Petroleum Society of Canada. doi:10.2118/2003-201

Badley, M. E., Freeman, B., Roberts, A. M., Thatcher, J. S., Walsh, J. J., Watterson, J. \& Yielding, G. 1990. Fault interpretation during seismic interpretation and reservoir evaluation. In: The integration of geology, geophysics, petrophysics, and petroleum engineering in reservoir delineation, description, and management. Proceedings of the 1st Archie Conference, Houston, Texas. Association of American Petroleum Geologists, 224-241.

Barry, R. A. (1963, April 1). A Material-Balance Technique for Undersaturated, Partially Water-Driven Reservoirs. Society of Petroleum Engineers. doi :10.2118/466-PA
Bashiri, A., \&Kasiri, N. (2010). A combinatorial mathematical model to simulate performance of naturally fractured reservoir. Oil and Gas Journal.

Bashiri, A., \&Kasiri, N. (2011, January 1). Revisit Material Balance Equation for Naturally Fractured Reservoirs. Society of Petroleum Engineers.

Ben E. Law and Charles W. Spencer, 1993, "Gas in tight reservoirs-an emerging major source of energy," in David G. Howell (ed.), The Future of Energy Gasses, US Geological Survey, Professional Paper 1570, p.233-252.

Blasingame, T.A, McCray, T.L, Lee, W.J: "Decline Curve Analysis for Variable Pressure Drop/Variable Flowrate Systems," paper SPE 21513 presented at the SPE Gas Technology Symposium, 23-24 January 1991.

Buduka, S., Biu, V. T., \& Sylvester, O. (2015, August 4). A Time Function Havlena and Odeh MBE Straight Line Equation. Society of Petroleum Engineers.

Campbell, R.A., 1978. Mineral Property Economics, Publishing Property Evaluation, Campbell Petroleum Series, Vol.3

Carlson, E.S. and Mercer, J.C., "Devonian Shale Gas production: mechanisms and Simple Models," SPE 19311, 1989 (also JPT April 1991).

CherifKhelifa, AziezZeddouri and FayçalDjabes (2014), Influence of Natural Fractures on Oil Production of Unconventional Reservoirs, Energy Procedia, Volume 50, Pages 360-367, ISSN 1876-6102,

Coward, M. P., Daltaban, T. S. \& Johnson, H. (eds) 1998. Structural geology in reservoir characterization. Geological Society, London, Special Publications, 127.

Craft, B.C., Hawkins, M.F., Jr., and Terry, R.E.:Applied Petroleum Reservoir Engineering. Second edition. PrenticeHall, Inc., New Jersey (1991).

Dake, L.P.: Fundamentals of Reservoir Engineering, Published by Elsevier Scientific Publishing Company, 1978

Dake, L.P.:The Practice of Reservoir Engineering. Developments in Petroleum Science 36, Elsevier Science B.V. (1994).

Duarte, J. C., Vinas, E. C., \&Ciancaglini, M. (2014, May 21). Material Balance Analysis of Naturally or Artificially Fractured Shale Gas Reservoirs to Maximize Final Recovery. Society of Petroleum Engineers.

England, W.A., 2002. Empirical correlations to predict gas/gascondensate phase behavior in sedimentary basins, Organic Geochemistry, Volume 3, Issue 6, Pages 665-673.

Engler, T. W. (2000, January 1). A New Approach to Gas Material Balance in Tight Gas Reservoirs. Society of Petroleum Engineers. 
Fattah, K.A., 2009. New Correlations calculate volatile oil, gas condensate PVT properties.

Fetkovich, M.J., Reese, D.E., and Whitson, C.H. (1991) Application of a General Material Balance for High-Pressure Gas Reservoir. Paper SPE 22921, presented at the 1991 SPE Annual Technical Conference and Exhibition, Dallas, October 6-9.

Fetkovich, M.J., Reese, D.E. and Whitson, C.H. (1998) Application of a General Material Balance for High-Pressure Gas Reservoir, SPE Journal, (March), pp. 3-13.

Lawal, A. S., \&Frailey, S. M. (2004). Material balance reservoir model for CO 2 sequestration in depleted gas reservoirs. 3495-3498. Paper presented at 2004 SPE Annual Technical Conference and Exhibition, Houston, TX, United States.

Frantz, J. H., \& Schlumberger, V. J. (2005). White paper on shale gas. Schlumberger Marketing Committee, 1-10.

Frederick, J. L., \& Kelkar, M. G. (2005, January 1). Decline Curve Analysis for Solution Gas Drive Reservoirs. Society of Petroleum Engineers. doi:10.2118/94859-MS

Gerami, S., Pooladi-Darvish, M., \&Mattar, L. (2007, January). Decline curve analysis for naturally fractured gas reservoirs: A study on the applicability of" pseudo-time" and" material balance pseudo-time". In International Petroleum Technology Conference. International Petroleum Technology Conference, 4-6 December 2007, Dubai, UAE.

Gonzalez, F. E., Ilk, D., \& Blasingame, T. A. (2008, January 1). A Quadratic Cumulative Production Model for the Material Balance of an Abnormally Pressured Gas Reservoir. Society of Petroleum Engineers. doi:10.2118/114044-MS

Guzman, J. D., Arevalo, J. A., \&Espinola, O. (2014, June 9). Reserves Evaluation of Dry Gas Reservoirs through Flowing Pressure Material Balance Method. Society of Petroleum Engineers. doi :10.2118/169989-MS

Hagoort, J., Sinke, J., Dros, B., \&Nieuwland, F. (2000, January 1). Material Balance Analysis of Faulted and Stratified, Tight Gas Reservoirs. Society of Petroleum Engineers.

HALL, H.N., Compressibility of Reservoir Rocks; transactions of the American Institute of Mechanical Engineers, Vol. 98, pp. 309-311, 1953

Harris, P.M., Weber, L.J., 2006. Giant Hydrocarbon Reservoirs of the world, American Association of Petroleum Geologists (AAPG), First Edition, USA, 469 pp.

Hassan, A. M., \& Hossain, M. E. (2016, April 25). Coupling Memory-Based Diffusivity Model with Energy Balance Equation to Estimate Temperature Distributions During Thermal EOR Process. Society of Petroleum Engineers. doi :10.2118/182767-MS
Havlena, D. and Odeh, A.S. (1964) The Material Balance as an Equation of a Straight Line-Part II, Field Cases. JPT (July) 815, Trans., AIME, 231.

Havlena, D. and Odeh, A.S.: The Material Balance as an equation of a Straight-Line. JPT (Aug. 1963) 896-900, Trans. AIME 228

Hossain, M.E. Numerical Investigation of Memory-Based Diffusivity Equation: The Integro-Differential Equation. Arab J Sci Eng 41, 2715-2729 (2016).

Hossain, M. E., \& Islam, M. R. (2009). A comprehensive material balance equation with the inclusion of memory during rockfluid deformation. Advances in Sustainable Petroleum Engineering Science, 1(2), 141-162.

Hossain, M. E., Mousavizadegan, S. H., \& Islam, M. R. (2008, January 1). A New Porous Media Diffusivity Equation with the Inclusion of Rock and Fluid Memories. Society of Petroleum Engineers.

Hossain, M.E. (2008) An Experimental and Numerical Investigation of Memory-Based Complex Rheology and ock/Fluid Interactions, PhD dissertation, Dalhousie University, Halifax, Nova Scotia, Canada, April, pp. 793.

Hossain, M.E., Liu, L. and Islam, M.R., "Inclusion of the Memory Function in Describing the Flow of Shear-Thinning Fluids in Porous Media", International Journal of Engineering (IJE). Vol. 3, No. 5, (2009), pp. $458-477$.

Hossain, M.E., Mousavizadegan, S.H. and Islam, M.R., "Rock and Fluid Temperature Changes during Thermal Operations in EOR Processes", Journal Nature Science and Sustainable Technology. Vol. 2, No. 3, March, (2008), pp.347 - 378.

Hossain, M.E., Mousavizadegan, S.H., Ketata, C. and Islam, M.R. (2007) A Novel Memory Based Stress-Strain Model for Reservoir Characterization, Journal of Nature Science and Sustainable Technology, Vol. 1(4), pp. $653-678$.

Humphreys, N. V. (1991, January 1). The Material Balance Equation for a Gas Condensate Reservoir with Significant Water Vaporization. Society of Petroleum Engineers.

Hurst, W. (1974, January 1). The Material Balance Equation. Society of Petroleum Engineers.

Ibrahim, M., Fahmy, M., Salah, H., El-Said, M., \& El-Banbi, A. H. (2013, April 15). New Material Balance Equation Allows for Separator Conditions Changes during Production History. Society of Petroleum Engineers.

Ismadi, D., Kabir, C. S., \& Hasan, A. R. (2011, January 1). The Use of Combined Static and Dynamic Material-Balance Methods in Gas Reservoirs. Society of Petroleum Engineers.

Istayeva, U., \& King, G. (2014, November 12). Application of the Extended Dynamic Material Balance Method to a Super Giant 
Carbonate Oilfield. Society of Petroleum Engineers. doi :10.2118/172283-MS

Jensen, D., Smith, L.K., A Practical Approach to Coalbed Methane Reserve Prediction Using A Modified Material Balance Technique, paper 9765, Proceedings of the 1997 International Coalbed Methane Symposium, The University of Alabama, Tuscaloosa, Alabama, p. 105-113 (1997).

Jolley, S. J. (2007). Structurally complex reservoirs. Geological Society of London.

R. J. Knipe, G. Jones, and Q. J. Fisher(1998). Faulting, fault sealing, and fluid flow in hydrocarbon reservoirs: an introduction. Geological Society, London, Special Publications 147.

Kuppe, F., Chugh, S., \& Connell, P. (2000, January 1). Material Balance for Multi-layered, Commingled, Tight Gas Reservoirs. Society of Petroleum Engineers.

Lane, H. S., Watson, A. T., \& Lancaster, D. E. (1989, January 1). Identifying and Estimating Desorption from Devonian Shale Gas Production Data. Society of Petroleum Engineers.

Lonergan, L., Jolly, R. J. H., Rawnsley, K. \& Sanderson, D. J. (eds) 2007. Fractured Reservoirs. Geological Society, London, Special Publications, 270.

M. Caputo, Geothermics, "Diffusion of fluids in porous media with memory". 23: 113-130, 1999.

M. Caputo, Water Resources Research, "Models of Flux in porous media with memory". 36(3): 693-705, 2000.

Mattar, L., Anderson, D., \& Stotts, G. (2006, November 1). Dynamic Material Balance-Oil-or Gas-in-Place without ShutIns. Petroleum Society of Canada. doi:10.2118/06-11-TN

Mcclay, K. R. (ed.) 2004. Thrust Tectonics and Hydrocarbon Systems. American Association of Petroleum Geologists, Memoir, 82.

McNaughton, D.A. and GARB, F.A., Finding and Evaluating Petroleum Accumulations in Fractured Reservoir Rock; in Exploration and Economics of the Petroleum Industry, Vol. 13, Matthew Bender and Company Inc., New York, NY, 1975.

Miranda, A., \& Raghavan, R. (1975, October 1). Optimization of the Material Balance Equation. Petroleum Society of Canada. doi:10.2118/75-04-05

Miranda, A., \& Raghavan, R. (1975, October 1). Optimization of the Material Balance Equation. Petroleum Society of Canada.

Mittermeir, G. M. (2015, May 1). Material-Balance Method for Dual-Porosity Reservoirs with Recovery Curves to Model the Matrix/Fracture Transfer. Society of Petroleum Engineers.

Moghadam, S., Jeje, O., \&Mattar, L. (2009, January 1). Advanced Gas Material Balance, in Simplified Format. Petroleum Society of Canada.
Moller-Pedersen, P. \& Koestler, A. G. (eds) 1997. Hydrocarbon Seals: Importance for Exploration and Production. Norwegian Petroleum Society, Special Publication 7.

Morgan, M. D. (2010, January 1). Forecasting Tight Gas Well Production with a Material Balance Constraint. Society of Petroleum Engineers.

Mosobalaje, O. O., Onuh, C. Y., \&Seteyeobot, I. (2015, August 4). A New Solution Methodology to the Material Balance Equation, for Saturated Reservoirs. Society of Petroleum Engineers. doi:10.2118/178392-MS

Muskat, M.:Physical Principles of Oil Production. McGraw-Hill, New York (1949).

Nader, W. (1964, March 1). An Investigation Concerning the Material Balance Equation Part One: The Linear Form of the Equation. Petroleum Society of Canada.

Narr, W., Schechter D. W., Thompson L. B., 2006. Naturally Fractured Reservoir Characterization, SPE Publication, Texas, USA, 112 pp.

Needham, D. T., Yielding, G. \&Freeman, B. 1996. Analysis of fault geometry and displacement patterns. In: BUCHANAN, P. G. \& NIEUWLAND, D. A. (eds) Modern Developments in Structural Interpretation, Validation and Modelling. Geological Society, London, Special Publications, 99, 189-199.

Nelson, R.A. (1982, September 1). An Approach to Evaluating Fractured Reservoirs. Society of Petroleum Engineers. doi:10.2118/10331-PA

Nelson, R.A.:Geologic Analysis of Naturally Fractured Reservoirs. Gulf Publishing Company, Houston (1985).

Nobakht, M., Mattar, L., Moghadam, S., \& Anderson, D. M. (2010, January 1). Simplified yet Rigorous Forecasting of Tight/Shale Gas Production in Linear Flow. Society of Petroleum Engineers.

Ojo, K. P., Tiab, D., \&Osisanya, S. O. (2004, January 1). Dynamic Material Balance Equation and Solution Technique Using Limited Pressure Data. Petroleum Society of Canada. doi $: 10.2118 / 2004-119$

Ojo, K. P., Tiab, D., \&Osisanya, S. O. (2006, March 1). Dynamic Material Balance Equation and Solution Technique Using Production and PVT Data. Petroleum Society of Canada. doi :10.2118/06-03-03.

Orozco, D., \& Aguilera, R. (2017, February 1). A Material-Balance Equation for Stress-Sensitive Shale-Gas-Condensate Reservoirs. Society of Petroleum Engineers. doi :10.2118/177260-PA.

Penuela, G., Idrobo, E. A., Ordonez, A., Medina, C. E., \& Meza, N. S. (2001, January 1). A New Material-Balance Equation for 
Naturally Fractured Reservoirs Using a Dual-System Approach. Society of Petroleum.

Penuela, G., Ordonez, A., \&Bejarano, A. (1998, January 1). A Generalized Material Balance Equation for Coal Seam Gas Reservoirs. Society of Petroleum Engineers.

Peron, J. R. (2007, January 1). Material Balance of Fractured Fields--Double Reservoir Method. Society of Petroleum Engineers.

Pirson, S.J.:Oil reservoir Engineering. McGraw-Hill, New York (1958).

Poe Jr., B.D.: "Effective Well and Reservoir Evaluation Without the Need for Well Pressure History" paper SPE 77691 presented at the SPE Annual Conference and Technical Exhibition, October 2002

Rahman, N.M.A., Anderson, D.M. and Mattar, L. (2006) New Rigorous Material Balance Equation for Gas Flow in a Compressible Formation with Residual Fluid Saturation. SPE 100563, presented at the SPE Gas Technology Symposium held in Calgary, Alberta, Canada, May 15-17.

Ramagost, B.P. and Farshad, F.F. (1981) P/Z Abnormally Pressured Gas Reservoirs, paper SPE 10125 presented at SPE ATCE, San Antonio, TX, October 5-7.

Rashid, M. U. \& Hossain M.E. (2018) 'Development of a Modified Material Balance Equation for complex Reservoirs with the Inclusion of Fluid Velocity', Master's thesis, Memorial University of Newfoundland, Canada.

Rutten, K. W. \&Verschuren, M. A. J. 2003. Building and unfaulting fault-horizon networks. In: NIEUWLAND, D. A. (ed.) New Insights into Structural Interpretation and Modelling. Geological Society, London, Special Publications, 212, 39-57.

Sandoval Merchan, P. A., Calderon Carrillo, Z. H., \& Ordonez, A. (2009, January 1). The New, Generalized Material Balance Equation for Naturally Fractured Reservoirs. Society of Petroleum Engineers, Latin American and Caribbean Petroleum Engineering Conference, 31 May-3June 2009, Catagena de Indias, Colombia.

Schilthuis, R.J. : Active Oil and Reservoir Energy, Trans. AIME (1936) 148, 33-52.

Sills, S. R. (1996, May 1). Improved Material-Balance Regression Analysis for Waterdrive Oil and Gas Reservoirs. Society of Petroleum Engineers. doi :10.2118/28630-PA.
Singh, V. K. (2013, March 10). Overview of Material Balance Equation (MBE) in Shale Gas \& Non-Conventional Reservoir. Society of Petroleum Engineers.

Sorkhabi, R. \& Tsuji, Y. (eds) 2005. Faults, Fluid Flow, and Petroleum Traps. American Association of Petroleum Geologists, Memoir, 85.

Stevens, Paul (August 2012). "The 'Shale Gas Revolution': Developments and Changes".

Swennen, R., Roure, F. \&Granath, J. W. (eds) 2004. Deformation, Fluid Flow, and Reservoir Appraisal in Foreland Fold and Thrust Belts. American Association of Petroleum Geologists, Hedberg Series, 1, 1- 2.

Tian, S., \& Zhao, G. (2004, January 1). Monitoring and Predicting CO Flooding Using Material Balance Equation. Petroleum Society of Canada. doi :10.2118/2004-096.

Tracy, G. W. (1955, January 1). Simplified Form of the Material Balance Equation. Society of Petroleum Engineers.

Van Der Knaap, W., Nonlinear Behaviour of Elastic Porous Media; Petroleum Transactions of the American Institute of Mechanical Engineers, Vol. 216, pp. 179-187, 1959.

Walsh, M.P.: A Generalized Approach to Reservoir Material Balance Calculations, JCPT (Jan. 1995) 55-63.

Walton, I., \& McLennan, J. (2013, May 20). The Role of Natural Fractures in Shale Gas Production. International Society for Rock Mechanics.

Wang, S. W., Stevenson, V. M., Ohaeri, C. U., \&Wotring, D. H. (1999, January 1). Analysis of Overpressured Reservoirs with A New Material Balance Method. Society of Petroleum Engineers. doi :10.2118/56690-MS

Wang, S.-W. (1998, January 1). A General Linear Material Balance Method for Normally and Abnormally Pressured Petroleum Reservoirs. Society of Petroleum Engineers. doi :10.2118/48954-MS.

Warner, H. R., Hardy, J. H., Robertson, N., \& Barnes, A. L. (1979, HAugust 1). University Block 31 Field Study: Part 1 - Middle Devonian Reservoir History Match. Society of PetroleumEngineers. 